\title{
ERRATUM
}

\section{Protecting Culture and Marine Ecosystems Under the Law in Micronesia-ERRATUM}

doi: $10.1017 /$ S0940739112000161

The author’s email address is listed as Sam.Edwards.3@gramil.com.

It should read: Sam.Edwards.3@gmail.com.

\section{BIBLIOGRAPHY}

Edwards, Sam. "Protecting Culture and Marine Ecosystems Under the Law in Micronesia." International Journal of Cultural Property 19 (2012): 197-216.

The publisher regrets the error. 